УДК 536.25

\title{
Modeling of Two-layer Fluid Flows with Evaporation at the Interface in the Presence of the Anomalous Thermocapillary Effect
}

\author{
Olga N. Goncharova* \\ Ekaterina V. Rezanova ${ }^{\dagger}$ \\ Altai State University \\ Lenina, 61, Barnaul, 656049
}

Russia

Received 02.10.2015, received in revised form 16.12.2015, accepted 20.01.2016

Stationary convective flows of two immiscible viscous incompressible fluids (liquid and gas) under action of the transverse gravity field and longitudinal temperature gradient along the interface are studied analytically. Mathematical model of the fluid flows with the effects of evaporation at the interface is based on exact solutions to the Navier-Stokes equations in the Oberbeck-Boussinesq approximation. The effects of the thermodiffusion and diffusive heat conductivity in the gas-vapor layer are taken into consideration. The obtained solutions are used to model the flows in the two-layer gas-liquid system in the case when a liquid exhibits the anomalous thermocapillary effect. Examples of the two-layer fluid flows are presented for various values of the gas flow rate, longitudinal temperature gradient at the interface and the gravity force acceleration.

Keywords: mathematical model, interface, evaporation, exact solution, anomalous thermocapillary effect. DOI: $10.17516 / 1997-1397-2016-9-1-48-59$.

\section{Introduction}

Stationary two-layer fluid flows are studied on the basis of exact solutions to the NavierStokes equations in the Oberbeck-Boussinesq approximation in two-dimensional case [1-3]. The solutions are obtained in the case when only the longitudinal velocity is not equal to zero and it depends on the transverse coordinate. The temperature distribution and pressure in the upper and lower layers have the components which linearly depend on the longitudinal coordinate. The longitudinal gradients of temperature and vapor concentration depend linearly on the transverse coordinate. The longitudinal pressure gradient is a quadratic function with respect to the longitudinal coordinate. One of the first results devoted to construction of an exact solution in the infinite layer with evaporation at the "liquid-liquid" interface were obtained in [4]. The thermocapillarity effect at the interface has not been taken into consideration. The solution has been used to model the binary flows with diffusion of the light impurity at interface [4].

The mentioned here solutions (see [1,2,4]) are solutions of the Birikh-Ostroumov type [5]. The solution of Birikh [5] has been constructed to describe the stationary convection in an infinite horizontal strip with solid boundaries or with a non-deformable free boundary under the action

\footnotetext{
*gon@math.asu.ru

$\dagger$ katerezanova@mail.ru

(c) Siberian Federal University. All rights reserved
} 
of the gravity field and constant longitudinal temperature gradient (see also [6-8]). For the first time the similar problem has been studied in [9].

In the present paper the Soret and Dufour effects $[10,11]$ are taken into consideration in the gas-vapor layer (see [3]). The exact solutions allow us to analyze the problem statements and peculiarities of modeling of flow effects including the effect of anomalous thermocapillary which attracts attention due to its importance for many liquids [12-16]. One of the main questions in modeling of fluid flows in channels is the formulation of a condition for vapor concentration on the upper solid wall of the channel. In the present paper the condition of the absence of the vapor flux is assumed to be fulfilled on this boundary of the flow domain. It is also shown that the constructed solutions can be used to model flows in the two-layer system when liquid exhibits the anomalous thermocapillary effect.

\section{Governing equation}

The coordinate system $(x, y)$ is chosen so that the vector of the gravity acceleration $\mathbf{g}$ is directed opposite to the $O y$ axis $(\mathbf{g}=(0,-g))$. In order to formulate our problem in dimensionless form we introduce characteristic values of the problem as follows: the thickness of the liquid layer $l$ is the characteristic length, $u_{*}=\nu_{1} / l$ is the characteristic velocity, $T_{*}$ is the characteristic temperature drop, $p_{*}=\rho_{1} \nu_{1}^{2} / l^{2}$ is the characteristic pressure; here $\rho_{1}$ and $\nu_{1}$ are the density and the coefficient of the kinematic viscosity of the liquid, respectively. The system of two viscous incompressible fluids (liquid and gas-vapor mixture) fills the infinite horizontal layers with the upper and lower boundaries $y=h, y=-1$ and plane $y=0$ which is the thermocapillary interface (see Fig. 1). Index 1 (superscript or subscript) is used to characterize the properties of the liquid and index 2 is used to characterize the gas properties.

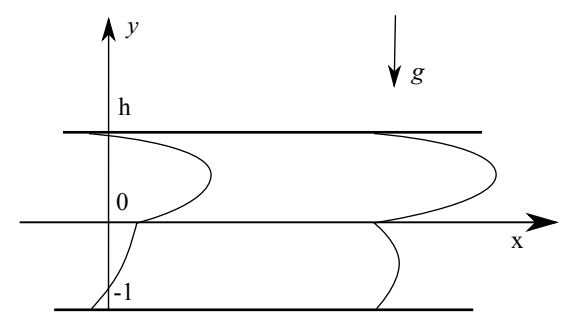

Fig. 1. Geometry of fluid flow domains

The two-dimensional stationary convective fluid flows are characterized by the velocity field $\left(u^{i}, v^{i}\right)$, pressure $p^{i}$, temperature $T^{i}$ and vapor concentration $C$ which satisfy the OberbeckBoussinesq approximation of the Navier-Stokes equations. The convective flows of the liquid in the lower layer are described by the system of equations which can be presented in the following dimensionless form:

$$
\begin{gathered}
u^{1} u_{x}^{1}+v^{1} u_{y}^{1}=-\bar{p}_{x}^{1}+\Delta u^{1}, \\
u^{1} v^{1}{ }_{x}+v^{1} v^{1}{ }_{y}=-\bar{p}_{y}^{1}+\Delta v^{1}+G r T^{1}, \\
u_{x}^{1}+v_{y}^{1}=0, \\
u^{1} T^{1}{ }_{x}+v^{1} T_{y}^{1}=\frac{1}{\operatorname{Pr}} \Delta T^{1} .
\end{gathered}
$$


The stationary flows in the upper gas-vapor layer (see Fig. 1) are described by the following equations:

$$
\begin{gathered}
u^{2} u_{x}^{2}+v^{2} u_{y}^{2}=-\frac{1}{\bar{\rho}} \bar{p}_{x}^{2}+\bar{\nu} \Delta u^{2}, \\
u^{2} v_{x}^{2}+v^{2} v_{y}^{2}=-\frac{1}{\bar{\rho}} \bar{p}_{y}^{2}+\bar{\nu} \Delta v^{2}+G r \bar{\beta} T^{2}+G r_{c} \bar{\nu}^{2} C, \\
u_{x}^{2}+v_{y}^{2}=0, \\
u^{2} T_{x}^{2}+v^{2} T_{y}^{2}=\frac{\bar{\chi}}{P r}\left(\Delta T^{2}+\bar{\delta} \Delta C\right), \\
u^{2} C_{x}+v^{2} C_{y}=\frac{\bar{\nu}}{S c}\left(\Delta C+\bar{\alpha} \Delta T^{2}\right) .
\end{gathered}
$$

Here $\bar{p}^{i}$ is the modified pressure, $\bar{p}^{1}=p^{1}+G r /\left(\beta_{1} T_{*}\right) y, \bar{p}^{2}=p^{2}+G r \bar{\rho} /\left(\beta_{1} T_{*}\right) y$. The following dimensionless parameters arise in the problem: $G r=\beta_{1} T_{*} g l^{3} / \nu_{1}^{2}$ is the Grashof number, $G r_{c}=$ $\gamma g l^{3} / \nu_{2}^{2}, \operatorname{Pr}=\nu_{1} / \chi_{1}$ is the Prandtl number, $S c=\nu_{2} / D$ is the Schmidt number, $\bar{\nu}=\nu_{2} / \nu_{1}$ is the ratio of the coefficients of the kinematic viscosity, $\bar{\rho}=\rho_{2} / \rho_{1}$ is the ratio of the gas and liquid densities, $\bar{\chi}=\chi_{2} / \chi_{1}$ is the ratio of the coefficients of thermal conductivity of gas and liquid, $D$ is the coefficient of vapor diffusion, $\beta_{i}$ is the thermal expansion coefficient $(i=1,2), \gamma$ is the concentration expansion coefficient, $\bar{\delta}=\delta / T_{*}, \bar{\alpha}=\alpha T_{*}$, coefficients $\delta$ and $\alpha$ characterize the Dufour and Soret effects, respectively.

Let us assume that solution of systems (1) and (2) has the form

$$
\begin{gathered}
u^{i}=u^{i}(y), \quad v^{i}=0 \\
T^{i}=\left(a_{1}^{i}+a_{2}^{i} y\right) x+\vartheta_{i}(y), \quad C=\left(b_{1}+b_{2} y\right) x+\phi(y) .
\end{gathered}
$$

Because temperature is continuous at the interface $y=0$ we have $a_{1}^{1}=a_{1}^{2}=A, A=$ const (see section 2.). Then exact solutions (3) of system of equations (1), (2) can be written as follows:

$$
\begin{gathered}
u^{1}=\frac{y^{4}}{24} G r a_{2}^{1}+\frac{y^{3}}{6} G r A+\frac{y^{2}}{2} c_{1}+y c_{2}+c_{3} . \\
T^{1}=\left(A+a_{2}^{1} y\right) x+\frac{y^{7}}{1008} \frac{G r\left(a_{2}^{1}\right)^{2}}{(1 / P r)}+\frac{y^{6}}{144} \frac{G r A a_{2}^{1}}{(1 / P r)}+\frac{y^{5}}{120} \frac{1}{(1 / P r)}\left(G r(A)^{2}+3 a_{2}^{1} c_{1}\right)+ \\
+\frac{y^{4}}{24} \frac{1}{(1 / P r)}\left(A c_{1}+2 a_{2}^{1} c_{2}\right)+\frac{y^{3}}{6} \frac{1}{(1 / P r)}\left(A c_{2}+a_{2}^{1} c_{3}\right)+\frac{y^{2}}{2} \frac{A}{(1 / P r)} c_{3}+y c_{4}+c_{5}, \\
\bar{p}^{1}=\left(\frac{y^{2}}{2} G r a_{2}^{1}+y G r A+c_{1}\right) x+\frac{y^{8}}{8} k_{7}+\frac{y^{7}}{7} k_{6}+\frac{y^{6}}{6} k_{5}+\frac{y^{5}}{5} k_{4}+\frac{y^{4}}{4} k_{3}+\frac{y^{3}}{3} k_{2}+\frac{y^{2}}{2} k_{1}+y k_{0}+c_{8}, \\
u^{2}=\frac{y^{4}}{24} \frac{1}{\bar{\nu}}\left(G r \bar{\beta} a_{2}^{2}+G r_{c} \bar{\nu}^{2} b_{2}\right)+\frac{y^{3}}{6} \frac{1}{\bar{\nu}}\left(G r \bar{\beta} A+G r_{c} \bar{\nu}^{2} b_{1}\right)+\frac{y^{2}}{2} \bar{c}_{1}+y \bar{c}_{2}+\bar{c}_{3}, \\
+\frac{y^{6}}{720}\left[\frac{B_{1}}{\bar{\nu}}\left(G r \bar{\beta} a_{2}^{2}+G r_{c} \bar{\nu}^{2} b_{2}\right)+4 \frac{B_{2}}{\bar{\nu}}\left(G r \bar{\beta} A+G r_{c} \bar{\nu}^{2} b_{1}\right)\right]+\frac{y^{5}}{120}\left[\frac{B_{1}}{\bar{\nu}}\left(G r \bar{\beta} A+G r_{c} \bar{\nu}^{2} b_{1}\right)+\right. \\
\left.+3 B_{2} \bar{c}_{1}\right]+\frac{y^{4}}{24}\left[B_{1} \bar{c}_{1}+2 B_{2} \bar{c}_{2}\right]+\frac{y^{3}}{6}\left[B_{1} \bar{c}_{2}+B_{2} \bar{c}_{3}\right]+\frac{y^{2}}{2} B_{1} \bar{c}_{3}+y \bar{c}_{4}+\bar{c}_{5}, \\
C=\left(b_{1}+b_{2} y\right) x+\frac{y^{7}}{1008} \frac{E_{2}}{\bar{\nu}}\left(G r \bar{\beta} a_{2}^{2}+G r_{c} \bar{\nu}^{2} b_{2}\right)+\frac{y^{6}}{720} \frac{1}{\bar{\nu}}\left\{E_{1}\left(G r \bar{\beta} a_{2}^{2}+G r_{c} \bar{\nu}^{2} b_{2}\right)+\right. \\
\left.+4 E_{2}\left(G r \bar{\beta} A+G r_{c} \bar{\nu}^{2} b_{1}\right)\right\}+\frac{y^{5}}{120}\left\{\frac{E_{1}}{\bar{\nu}}\left(G r \bar{\beta} A+G r_{c} \bar{\nu}^{2} b_{1}\right)+3 E_{2} \bar{c}_{1}\right\}+ \\
+\frac{y^{4}}{24}\left\{E_{1} \bar{c}_{1}+E_{2} \bar{c}_{2}\right\}+\frac{y^{3}}{6}\left\{E_{1} \bar{c}_{2}+E_{2} \bar{c}_{3}\right\}+\frac{y^{2}}{2} E_{1} \bar{c}_{3}+y \bar{c}_{6}+\bar{c}_{7},
\end{gathered}
$$




$$
\begin{gathered}
\bar{p}^{2}=\left[\frac{y^{2}}{2}\left(\bar{\rho} G r \bar{\beta} a_{2}^{2}+\bar{\rho} G r_{c} \bar{\nu}^{2} b_{2}\right)+y\left(\bar{\rho} G r \bar{\beta} A+\bar{\rho} G r_{c} \bar{\nu}^{2} b_{1}\right)+\bar{\rho} \bar{\nu} \bar{c}_{1}\right] x+ \\
+\frac{y^{8}}{8} \bar{k}_{7}+\frac{y^{7}}{7} \bar{k}_{6}+\frac{y^{6}}{6} \bar{k}_{5}+\frac{y^{5}}{5} \bar{k}_{4}+\frac{y^{4}}{4} \bar{k}_{3}+\frac{y^{3}}{3} \bar{k}_{2}+\frac{y^{2}}{2} \bar{k}_{1}+y \bar{k}_{0}+\bar{c}_{8} .
\end{gathered}
$$

The coefficients $B_{1}=\frac{(\bar{\nu} / S c) A-(\bar{\chi} / \operatorname{Pr}) \bar{\delta} b_{1}}{(\bar{\nu} / S c) \chi_{2}(1-\bar{\alpha} \bar{\delta})}, B_{2}=\frac{(\bar{\nu} / S c) a_{2}^{2}-(\bar{\chi} / \operatorname{Pr}) \bar{\delta} b_{2}}{(\bar{\nu} / S c)(\bar{\chi} / \operatorname{Pr})(1-\bar{\alpha} \bar{\delta})}, E_{1}=\left[\frac{b_{1}}{(\bar{\nu} / S c)}-\right.$ $\left.\bar{\alpha} B_{1}\right], E_{2}=\left[\frac{b_{2}}{(\bar{\nu} / S c)}-\bar{\alpha} B_{2}\right], k_{i}, \bar{k}_{i}(i=0, \ldots, 7)$ in expressions (6), (10) for $\bar{p}^{i}$ and in expressions (8), (9) for $T^{2}$ and $C$ depend on the initial parameters of the problem such as $\rho_{i}, \nu_{i}, \chi_{i}, \beta_{i}, D, \gamma, g$ $(i=1,2)$. The values of the integration coefficients $c_{i}, \bar{c}_{i}(i=1, \ldots, 8)$, and relations for parameters $b_{1}, b_{2}, a_{j}^{i}(i, j=1,2)$ (see the form of exact solution (3)) are determined by the boundary conditions.

\section{Boundary conditions and algorithm for computing the integration constants}

Let us assume that the gas flow rate in the upper layer $Q$ is given $Q=\int_{0}^{h} u^{2}(y) d y$. The characteristic value $Q_{*}$ of the gas flow rate is equal to $\rho_{2} u_{*} l$. On the solid walls $y=-1$ and $y=h$ of the channel the no-slip conditions should be fulfilled: $\left.u^{1}\right|_{y=-1}=0,\left.\quad u^{2}\right|_{y=h}=0$. We assume that the vapor concentration on the upper boundary $y=h$ satisfies the condition of the absence of the vapor flux $\left.\left(C_{y}\right)\right|_{y=h}=0$ and the temperature boundary regime is determined as follows. The lower solid boundary $y=-1$ is assumed to be the heat-insulating wall: $\left.\left(T_{y}^{1}\right)\right|_{y=-1}=0$. The constant heat flux is maintained on the upper wall $y=h:\left.\left(T_{y}^{2}\right)\right|_{y=h}=\theta^{+}$.

We suppose that the interface $y=0$ is the thermocapillary surface that remains to be undeformed one. The continuity of the velocity and temperature are written as follows: $\left.u^{1}\right|_{y=0}=\left.u^{2}\right|_{y=0},\left.\quad T^{1}\right|_{y=0}=\left.T^{2}\right|_{y=0}$. The heat transfer condition includes the diffusive vapor flux at the interface: $\left.\left(T_{y}^{1}-\bar{\kappa} T_{y}^{2}-\bar{\delta} \bar{\kappa} C_{y}\right)\right|_{y=0}=-\bar{\lambda} M$. The mass balance equation at the interface is of the form: $M=-\left.\left(C_{y}+\bar{\alpha} T_{y}^{2}\right)\right|_{y=0}$. Here $\bar{\kappa}=\kappa_{2} / \kappa_{1}, \kappa_{i}$ is the heat conductivity coefficient of the fluid, $\bar{\lambda}=\lambda M_{*} l /\left(\kappa_{1} T_{*}\right), \lambda$ is the latent heat of evaporation, $M_{*}$ is the characteristic value of the mass of the liquid evaporated from unit surface area per unit time, $M_{*}=D \rho_{2} / l$.

The saturated vapor concentration can be found with the help of relation $\left.C\right|_{y=0}=C_{*}[1+$ $\left.\bar{\varepsilon}\left(\left.T^{2}\right|_{y=0}-T_{0}\right)\right], C_{*}$ is the saturated vapor concentration at $T^{2}=T_{0}, \bar{\varepsilon}=\varepsilon T_{*}, \varepsilon$ is the parameter that includes the molar mass of the evaporated liquid, the universal gas constant, the latent heat of evaporation and $T_{0}[1,2]$.

We assume that surface tension linearly depend on temperature:

$$
\sigma=1-\bar{\sigma}_{T}\left(T^{1}-\bar{T}\right)
$$

Here $\bar{\sigma}_{T}=M a C a / P r, M a=\sigma_{T} T_{*} l /\left(\rho_{1} \nu_{1} \chi_{1}\right)$ is the Marangoni number, $C a=u_{*} \rho_{1} \nu_{1} / \sigma_{0}$ is the capillary number, $\operatorname{Pr}=\nu_{1} / \chi_{1}$ is the Prandtl number. The dimensional parameters $\sigma_{0}, \sigma_{T}$ are constants, $\sigma_{0}$ is the value of surface tension at some reference temperature and $\sigma_{T}$ is the temperature coefficient of the surface tension.

In the case of normal thermocapillary effect at the interface we have

$$
\bar{\sigma}_{T}=\bar{\sigma}(\bar{\sigma}>0), \text { for } T^{1} \leqslant \bar{T} .
$$


If the liquid exhibits the anomalous thermocapillary effect the coefficient of the surface tension can grow with temperature $[10,12,13]$ (see also $[14,17]$ ), so that the coefficient $\bar{\sigma}_{T}$ (see $(11)$ ) has the following value:

$$
\bar{\sigma}_{T}=-\bar{\sigma}(\bar{\sigma}>0), \text { for } T^{1}>\bar{T} .
$$

The parabolic dependence of the surface tension on temperature with a minimum at a temperature interval was presented [12-14].

The kinematic condition at the interface is fulfilled automatically because the normal component of the velocity vector is equal to zero at the interface $y=0$ due to (3). Projection of the dynamic condition (see, for example, [10]) on the normal and tangential vectors to the interface $y=0$ gives the following relations: $p^{1}=p^{2}, u_{y}^{1}=\bar{\rho} \bar{\nu} u_{y}^{2}-\bar{\sigma}_{T} A$.

We note that $\left.T^{1}\right|_{y=0}=A x+c_{5}$. Then conditions (12), (13) allow us to find the coordinate

$$
\bar{x}=\left(\bar{T}-c_{5}\right) / A .
$$

The inequality $T_{1} \leqslant \bar{T}$ (see (12)) is fulfilled for $x \leqslant \bar{x}$ if $A>0$. If $A<0$, this inequality is fulfilled for $x \geqslant \bar{x}$. In this case the choice of the value $\sigma_{T}$ is determined according to (12).

\subsection{Algorithm for computing the integration constants}

A1. In the case when the condition of the flux absence is prescribed for vapor concentration $C$ at the wall $y=h$, the equalities $b_{2}=0$ and $\phi^{\prime}(h)=0$ should be satisfied (the prime denotes the derivative with respect to $y$ ).

A2. The continuity conditions for velocity and temperature at the interface $y=0$ require $c_{3}=\bar{c}_{3}, c_{5}=\bar{c}_{5}$ and $a_{1}^{1}=a_{1}^{2}=A$.

A3. Taking into account the thermal insulation of the wall $y=-1$ and the boundary regime on $y=h$, we have $a_{2}^{1}=0, \theta_{1}^{\prime}(-1)=0$ and $a_{2}^{2}=0, \theta_{2}^{\prime}(h)=\theta^{+}$, respectively.

A4. The equation of mass balance and the heat transfer condition at the interface $y=0$ result in the following relations: $M=-\left(\bar{c}_{6}+\bar{\alpha} \bar{c}_{4}\right), b_{2}+\bar{\alpha} a_{2}^{2}=0, a_{2}^{1}-\bar{\kappa} a_{2}^{2}-\bar{\delta} \bar{\kappa} b_{2}=0$, $c_{4}-\bar{\kappa} \bar{c}_{4}-\bar{\delta} \bar{\kappa} \bar{c}_{6}=-\bar{\lambda} M$ (two of them are fulfilled identically).

A5. The condition for the saturated vapor concentration is fulfilled if the longitudinal temperature and concentration gradients $A$ and $b_{1}$, constants $\bar{c}_{7}$ and $\bar{c}_{5}$ are related as follows: $b_{1}=C_{*} \bar{\varepsilon} A, \bar{c}_{7}=C_{*}+C_{*} \bar{\varepsilon}\left(\bar{c}_{5}-T_{0}\right)$.

A6. The dynamic conditions at the interface result in relations between $c_{i}$ and $\bar{c}_{i}(i=1,2)$ : $c_{2}=\bar{c}_{2} \overline{\rho \nu}-\bar{\sigma}_{T} A, c_{1}=\bar{c}_{1} \bar{\rho} \bar{\nu}$.

A7. The system of linear algebraic equations for calculation of unknown constants $\bar{c}_{i}(i=1,2,3)$ follows from the no-slip conditions and the given gas flow rate. When $\bar{c}_{i}(i=1,2,3)$ are known the constants $c_{1}, c_{2}, c_{3}$ can be found.

A8. The integration constant $\bar{c}_{6}$ is determined from the equation $\phi^{\prime}(h)=0$ with the use of $\bar{c}_{i}$ $(i=1,2,3)$.

A9. Constant $c_{4}$ is determined from the equation $\theta_{1}^{\prime}(-1)=0$ when $c_{1}, c_{2}, c_{3}$ are known.

A10. The integration constant $\bar{c}_{4}$ should satisfy the relation $\bar{c}_{4}=c_{4} /(\bar{\kappa}+\bar{\lambda} \bar{\alpha})-\bar{c}_{6}(\bar{\delta} \bar{\kappa}+\bar{\lambda}) /(\bar{\kappa}+$ $\bar{\lambda} \bar{\alpha})$. This relation is a consequence of the heat transfer and mass balance conditions at the interface $y=0$. 
A11. The given heat flux at the boundary $\mathrm{y}=\mathrm{h}$ leads to the relation

$$
\theta^{+}=\frac{h^{4}}{24} B_{1} \frac{1}{\bar{\nu}}\left(G r \bar{\beta} A+G r_{c} \bar{\nu}^{2} b_{1}\right)+\frac{h^{3}}{6} B_{1} \bar{c}_{1}+\frac{h^{2}}{2} B_{1} \bar{c}_{2}+h B_{1} \bar{c}_{3}+\bar{c}_{4} .
$$

This relation should be considered as a compatibility condition that follows from the form of exact solution (3).

A12. The mass velocity of the evaporated liquid at the interface can be found with the use of the mass balance equation when $\bar{c}_{4}$ and $\bar{c}_{6}$ are known.

Assume that $c_{5}$ is equal to zero $\left(c_{5}=0\right)$. Then the coordinate $\bar{x}$ on the $O x$ axis is $\bar{x}=\bar{T} / A$ (see 14). The presented algorithm (A1)-(A12) of calculation of the integration constants $c_{j}$ $(j=1, \ldots, 5)$ and $\bar{c}_{i}(i=1, \ldots, 7)$ should be used twice in order to get two sets of the integration constants. We denote them by $\left(c_{j}^{+}, \bar{c}_{i}^{+}\right)$for $\bar{\sigma}_{T}=\bar{\sigma}$ and $\left(c_{j}^{-}, \bar{c}_{i}^{-}\right)$for $\bar{\sigma}_{T}=-\bar{\sigma}(j=1,2,3,4, i=$ $1,2,3,4,6)$. Equation (15) is the condition for the parameter $\theta^{+}$. It determines the temperature boundary regime on the upper solid wall of the channel.

\section{Examples of the two-layer fluid flows}

We consider the two-layer system, where the lower and upper layers with equal thicknesses $l$ are filled by $n$-heptan and nitrogen, respectively $[12,13,18]$. The values of the physico-chemical parameters of the liquid and gas are presented in Tab. 1.

The Dufour and Soret parameters are $\delta=10^{-3}(\mathrm{~K})$ and $\alpha=-5 \cdot 10^{-3}(1 / \mathrm{K})$, respectively.

Table 1. Values of physico-chemical parameters of the liquid and gas

\begin{tabular}{|c|c|c|}
\hline Parameter & n-heptan & nitrogen \\
\hline$\rho, \mathrm{g} / \mathrm{cm}^{3}$ & 0.68 & $1.2 \cdot 10^{-3}$ \\
\hline$\nu, \mathrm{cm}^{2} / \mathrm{s}$ & $0.568 \cdot 10^{-2}$ & 0.15 \\
\hline$\kappa, \mathrm{kal} /(\mathrm{cm} \mathrm{s} \mathrm{K})^{2}$ & $0.3346 \cdot 10^{-3}$ & $0.65 \cdot 10^{-4}$ \\
\hline$\chi, \mathrm{cm}^{2} / \mathrm{s}$ & $\sim 10^{-3}$ & 0.3 \\
\hline$\sigma_{0}, \mathrm{dyne} / \mathrm{cm}$ & 44 & \\
\hline$\sigma_{T}, \mathrm{dyne} /(\mathrm{cm} \mathrm{K})$ & 0.133 & \\
\hline $\mathrm{D}, \mathrm{cm}^{2} / \mathrm{s}$ & $\sim 10^{-1}$ & \\
\hline$\lambda, \mathrm{kal} / \mathrm{g}$ & $\sim 10^{2}$ & \\
\hline$\varepsilon, 1 / \mathrm{K}$ & $\sim 10^{-2}-10^{-1}$ & \\
\hline$-\gamma$ & $\sim 10^{-1}-1$ & \\
\hline$\beta, 1 / \mathrm{K}$ & $\sim 10^{-3}$ & $0.337 \cdot 10^{-2}$ \\
\hline
\end{tabular}

We chose the thickness of the liquid layer $l=0.5 \mathrm{~cm}$ as the characteristic scale of the flow domain. Then $u_{*}=0.011 \mathrm{~cm} / \mathrm{s}$. Tab. 2 presents the values of the dimensionless parameters of the gas-liquid system. If the characteristic temperature drop is equal to $T_{*}=10 \mathrm{~K}$ then $G r \approx 40289, G r_{c} \approx-3379$ in the case of normal gravity $\left(g=981 \mathrm{~cm} / \mathrm{s}^{2}\right)$ and $G r \approx 402.89$, $G r_{c} \approx-33.79$ in the case of low gravity $\left(g=9.81 \mathrm{~cm} / \mathrm{s}^{2}\right)$. According to [13] (see also [14]) we chose the dimensional value $\bar{T}$ equal to $35^{\circ} \mathrm{C}$. It defines the behavior of the surface tension with respect to the temperature at the interface. 
We model the two-layer fluid flows for the system "n-heptane-nitrogen" in the case of positive values of the longitudinal temperature gradient $A: A=0.1 \mathrm{~K} / \mathrm{cm}, A=0.01 \mathrm{~K} / \mathrm{cm}$. The temperature coefficient of the surface tension $\bar{\sigma}_{T}$ changes sign at the point $\bar{x}$. The dimensional velocity profiles are shown in Fig. 2-6. The figure captions contain dimensional values of longitudinal temperature gradient, gas flow rate denoted with the same symbols $A$ and $Q$ as dimensionless quantities and gravity acceleration $g$.

Pictures 2 and 3 demonstrate the velocity profiles at various values of the longitudinal temperature gradient $A$ at the interface. The qualitative and quantitative differences of the flow structure and sharp differences in the fluid flows at the right and the left of the point $\bar{x}$ are observed with the increase of the longitudinal gradient $A$ (dimensional analog $X$ of the point $\bar{x}$ is equal to $3500(\mathrm{~cm})$ for flows demonstrated in Fig. 2 and $X=350(\mathrm{~cm})$ for flows in Fig. 3). The velocity value at the interface is equal to $U=0.25$ $\mathrm{cm} / \mathrm{s}$ if $A=0.1 \mathrm{~K} / \mathrm{cm}$ (see Fig. 3, solid line) and $U=1.16 \mathrm{~cm} / \mathrm{s}$ if $A=0.01 \mathrm{~K} / \mathrm{cm}$ (see Fig. 2, solid line). Here the temperature coefficient of surface tension is equal to $\sigma_{T}=0.133$ dyne $/(\mathrm{cm} \mathrm{K}$ ) (in the dimensionless case we have $\bar{\sigma}_{T}=0.03$ ). In the case of anomalous temperature dependence of Table 2. Values of dimensionless parameters of the gas-liquid system

\begin{tabular}{|c|c|}
\hline Parameter & Value \\
\hline $\bar{\rho}$ & $1.76 \cdot 10^{-3}$ \\
\hline $\bar{\nu}$ & 26.41 \\
\hline $\bar{\kappa}$ & 0.19 \\
\hline $\bar{\chi}$ & 397.35 \\
\hline $\bar{\beta}$ & 3.18 \\
\hline$P r$ & 7.52 \\
\hline$S c$ & 1.63 \\
\hline $\bar{\alpha}$ & $5 \cdot 10^{-2}$ \\
\hline $\bar{\delta}$ & $10^{-4}$ \\
\hline $\bar{\varepsilon}$ & 0.49 \\
\hline $\bar{\lambda}$ & 2.78 \\
\hline $\bar{\sigma}$ & 0.03 \\
\hline
\end{tabular}
the surface tension when $\sigma_{T}=-0.133$ dyne $/(\mathrm{cm}$ K) $\left(\bar{\sigma}_{T}=-0.03\right)$ the value of velocity at the interface is $U=2.85 \mathrm{~cm} / \mathrm{s}$ for $A=0.1 \mathrm{~K} / \mathrm{cm}($ Fig. 3 , dashed line) and $U=1.42 \mathrm{~cm} / \mathrm{s}$ for $A=0.01 \mathrm{~K} / \mathrm{cm}$ (Fig. 2, dashed line). Figs. 2 and 3 present the flows under conditions of normal gravity $\left(g=981 \mathrm{~cm} / \mathrm{s}^{2}\right)$ in the case that the thickness of the gas and liquid layer is equal to $0.5 \mathrm{~cm}$, dimensional gas flow rate is $Q=1.8 \cdot 10^{-3} \mathrm{~g} /(\mathrm{cm} \mathrm{s})$. The dimensionless parameters are $h=1, l=1, Q=246.1, G r \approx 40289$. The values of velocity at the interface $U$ and of the mass rate of evaporated liquid $M$ are presented in Tab. 3 for various values of the longitudinal temperature gradients. More intensive evaporation is observed for larger value of the longitudinal temperature gradient and also in the case of anomalous effect of thermocapillarity. Fig. 4 demonstrates the flow structure in the system away from the point of change of thermocapillarity character $\bar{x}$ in the case that the longitudinal temperature gradient is equal to $A=0.1 \mathrm{~K} / \mathrm{cm}$.

A decrease of intensity of the gas flow rate results in quantitative and some qualitative differences in the flow (see Figs. 2 and 5 ). The velocity at the interface has the value $U=1.16$ (Fig. 2, solid line) and $U=0.025 \mathrm{~cm} / \mathrm{s}$ (Fig. 5, solid line) for positive value of temperature coefficient of the surface tension $\sigma_{T}=0.133\left(\bar{\sigma}_{T}=0.03\right)$ if the gas flow rate is equal to $Q=$ $1.8 \cdot 10^{-3} \mathrm{~g} /(\mathrm{cm} \mathrm{s})$ and $Q=1.8 \cdot 10^{-4} \mathrm{~g} /(\mathrm{cm} \mathrm{s})$, respectively. For negative value $\sigma_{T}=-0.133$ $\left(\bar{\sigma}_{T}=-0.03\right)$ the values of velocity at the interface are equal to $U=1.42$ (Fig. 2 , dashed line) and $U=0.28 \mathrm{~cm} / \mathrm{s} \mathrm{(Fig.} \mathrm{5,} \mathrm{dashed} \mathrm{line)} \mathrm{in} \mathrm{the} \mathrm{case} \mathrm{of} \mathrm{gas} \mathrm{flow} \mathrm{rate} Q=1.8 \cdot 10^{-3} \mathrm{~g} /(\mathrm{cm} \mathrm{s})$ and $Q=1.8 \cdot 10^{-4} \mathrm{~g} /(\mathrm{cm} \mathrm{s})$, respectively. Here $X=3500(\mathrm{~cm})$ for flows demonstrated in Fig. 2 and Fig. 5. Tab. 4 presents the values of the interface velocity $U$ and the mass rate of evaporated liquid $M$ for two values of the gas flow rate $Q=1.8 \cdot 10^{-3} \mathrm{~g} /(\mathrm{cm} \mathrm{s})$ and $Q=1.8 \cdot 10^{-4} \mathrm{~g} /(\mathrm{cm} \mathrm{s})$. It should be noted that for a larger value of the specific mass gas flow rate $Q$ the flow and 
evaporation processes are more intensive.

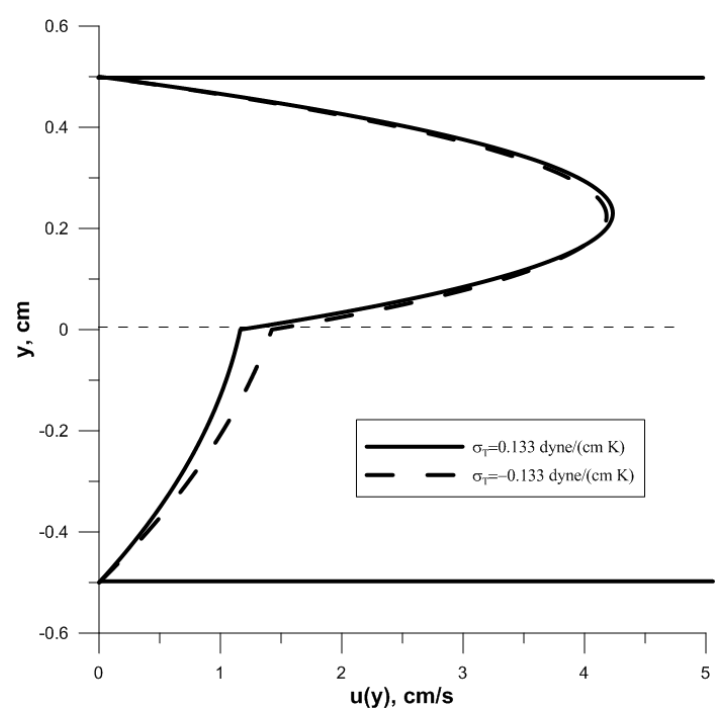

Fig. 2. Velocity profiles for positive and negative values of $\sigma_{T}$. Here $A=0.01 \mathrm{~K} / \mathrm{cm}, Q=$ $1.8 \cdot 10^{-3} \mathrm{~g} /(\mathrm{cm} \mathrm{s}), g=981 \mathrm{~cm} / \mathrm{s}^{2}$

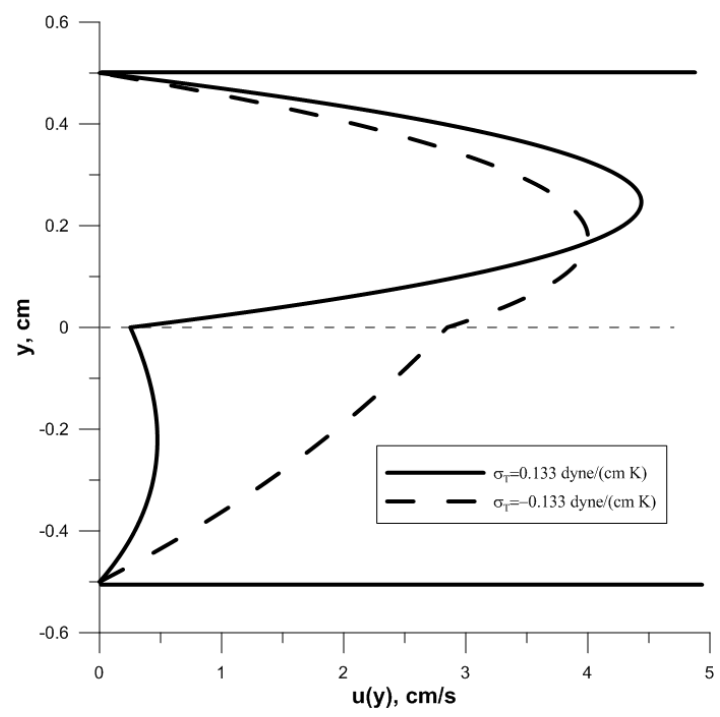

Fig. 3. Velocity profiles for positive and negative values of $\sigma_{T}$. Here $A=0.1 \mathrm{~K} / \mathrm{cm}, Q=$ $1.8 \cdot 10^{-3} \mathrm{~g} /(\mathrm{cm} \mathrm{s}), g=981 \mathrm{~cm} / \mathrm{s}^{2}$

The velocity profiles are presented in Fig. 6 in the case of low gravity $g=9.81 \mathrm{~cm} / \mathrm{s}^{2}$ $(G r \approx 402.89)$. Quantitative flow characteristics are changed slightly in comparison with the case $g=981 \mathrm{~cm} / \mathrm{s}^{2}$ (see Fig. 5). One can observe appearance of a reverse flow near the interface. The values $U$ and $M$ under normal $\left(g=981 \mathrm{~cm} / \mathrm{s}^{2}\right)$ and low gravity $\left(g=9.81 \mathrm{~cm} / \mathrm{s}^{2}\right)$ are presented in Tab. 5 in the case that $Q=1.8 \cdot 10^{-4} \mathrm{~g} /(\mathrm{cm} \mathrm{s}), A=0.01 \mathrm{~K} / \mathrm{cm}$. The value of the 
velocity at the interface $U$ is equal to $-0.003 \mathrm{~cm} / \mathrm{s}$ (Fig. 6 , solid line). The value of parameter $X$ is equal to $3500(\mathrm{~cm})$ for flows demonstrated in Fig. 5 and Fig. 6. Values of the mass of evaporated liquid are of the same order in the cases of normal and low gravity.

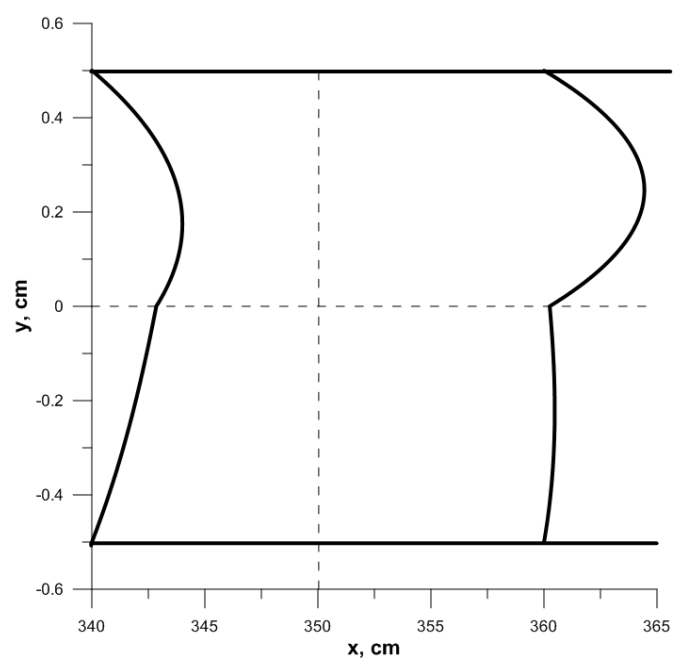

Fig. 4. Velocity profiles for positive and negative values of $\sigma_{T}$ (right and left). Here $A=$ $0.1 \mathrm{~K} / \mathrm{cm}, Q=1.8 \cdot 10^{-3} \mathrm{~g} /(\mathrm{cm} \mathrm{s}), g=981 \mathrm{~cm} / \mathrm{s}^{2}$

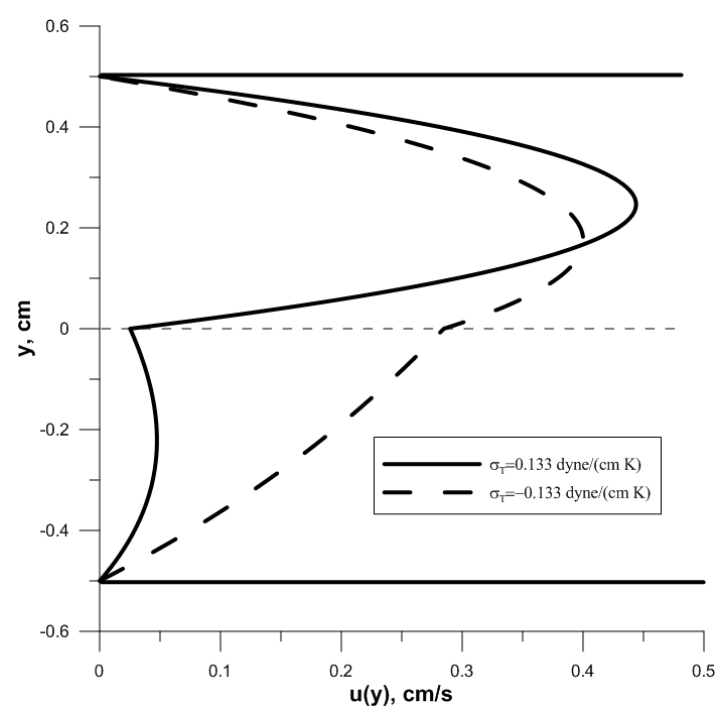

Fig. 5. Velocity profiles for positive and negative values of $\sigma_{T}$. Here $A=0.01 \mathrm{~K} / \mathrm{cm}, Q=$ $1.8 \cdot 10^{-4} \mathrm{~g} /(\mathrm{cm} \mathrm{s}), g=981 \mathrm{~cm} / \mathrm{s}^{2}$ 


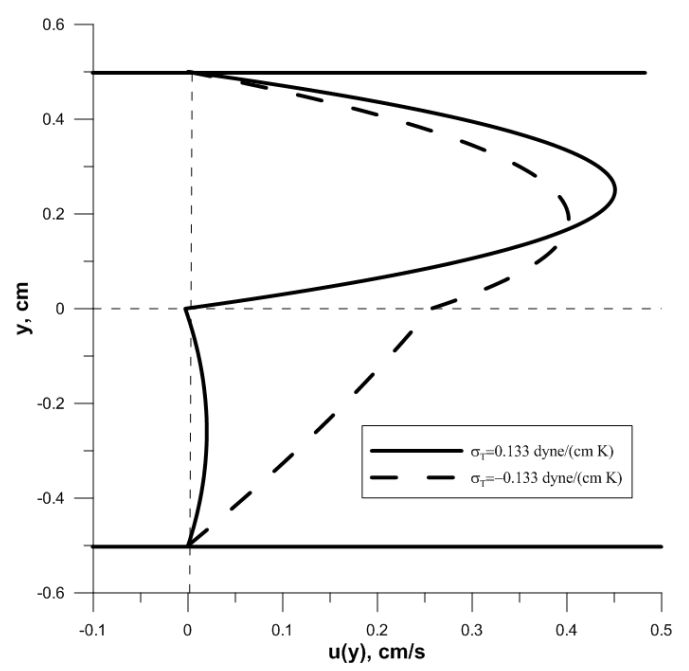

Fig. 6. Velocity profiles for positive and negative values of $\sigma_{T}$. Here $A=0.01 \mathrm{~K} / \mathrm{cm}, Q=$ $1.8 \cdot 10^{-4} \mathrm{~g} /(\mathrm{cm} \mathrm{s}), g=9.81 \mathrm{~cm} / \mathrm{s}^{2}$

Table 3. Values of interface velocity $U$ and mass rate of evaporated liquid $M ; Q=1.8 \cdot 10^{-3}$ $\mathrm{g} /(\mathrm{cm} \mathrm{s}), g=981 \mathrm{~cm} / \mathrm{s}^{2}$

\begin{tabular}{|c|c|c|c|c|}
\hline & \multicolumn{2}{|c|}{$\sigma_{T}=0.133$ dyne $/\left(\mathrm{cm} \mathrm{K}^{2}\right.$} & \multicolumn{2}{c|}{$\sigma_{T}=-0.133$ dyne $/(\mathrm{cm} \mathrm{K})$} \\
\hline$A, \mathrm{~K} / \mathrm{cm}$ & $U, \mathrm{~cm} / \mathrm{s}$ & $M, \mathrm{~g} /\left(\mathrm{cm}^{2} \mathrm{~s}\right)$ & $U, \mathrm{~cm} / \mathrm{s}$ & $M, \mathrm{~g} /\left(\mathrm{cm}^{2} \mathrm{~s}\right)$ \\
\hline 0.1 & 0.25 & $3.29 \cdot 10^{-4}$ & 2.85 & $1.45 \cdot 10^{-3}$ \\
\hline 0.01 & 1.16 & $6.45 \cdot 10^{-5}$ & 1.42 & $7.56 \cdot 10^{-5}$ \\
\hline
\end{tabular}

Table 4. Values of interface velocity $U$ and mass rate of evaporated liquid $M ; A=0.01 \mathrm{~K} / \mathrm{cm}$, $g=981 \mathrm{~cm} / \mathrm{s}^{2}$

\begin{tabular}{|c|c|c|c|c|}
\hline & \multicolumn{2}{|c|}{$\sigma_{T}=0.133$ dyne $/\left(\mathrm{cm} \mathrm{K}^{2}\right)$} & \multicolumn{2}{c|}{$\sigma_{T}=-0.133 \mathrm{dyne} /(\mathrm{cm} \mathrm{K})$} \\
\hline$Q, \mathrm{~g} /(\mathrm{cm} \mathrm{s})$ & $U, \mathrm{~cm} / \mathrm{s}$ & $M, \mathrm{~g} /\left(\mathrm{cm}^{2} \mathrm{~s}\right)$ & $U, \mathrm{~cm} / \mathrm{s}$ & $M, \mathrm{~g} /\left(\mathrm{cm}^{2} \mathrm{~s}\right)$ \\
\hline $1.8 \cdot 10^{-3}$ & 1.16 & $6.45 \cdot 10^{-5}$ & 1.42 & $7.56 \cdot 10^{-5}$ \\
\hline $1.8 \cdot 10^{-4}$ & 0.025 & $3.29 \cdot 10^{-6}$ & 0.28 & $1.45 \cdot 10^{-5}$ \\
\hline
\end{tabular}

Table 5. Values of interface velocity $U$ and mass rate of evaporated liquid $M ; Q=1.8 \cdot 10^{-4}$ $\mathrm{g} /(\mathrm{cm} \mathrm{s}), A=0.01 \mathrm{~K} / \mathrm{cm}$

\begin{tabular}{|c|c|c|c|c|}
\hline & \multicolumn{2}{|c|}{$\sigma_{T}=0.133$ dyne $/(\mathrm{cm} \mathrm{K})$} & \multicolumn{2}{c|}{$\sigma_{T}=-0.133$ dyne $/(\mathrm{cm} \mathrm{K})$} \\
\hline$g, \mathrm{~cm} / \mathrm{s}^{2}$ & $U, \mathrm{~cm} / \mathrm{s}$ & $M, \mathrm{~g} /\left(\mathrm{cm}^{2} \mathrm{~s}\right)$ & $U, \mathrm{~cm} / \mathrm{s}$ & $M, \mathrm{~g} /\left(\mathrm{cm}^{2} \mathrm{~s}\right)$ \\
\hline 981 & 0.025 & $3.29 \cdot 10^{-6}$ & 0.28 & $1.45 \cdot 10^{-5}$ \\
\hline 9.81 & -0.003 & $1.24 \cdot 10^{-6}$ & 0.26 & $1.24 \cdot 10^{-5}$ \\
\hline
\end{tabular}




\section{Conclusion}

The constructed solutions to the Navier-Stokes equations in the Oberbeck-Boussinesq approximation allow us to model the two-layer fluid flows with the thermocapillary interface including the evaporation effects at the interface and the Dufour and Soret effects in the gas-vapor phase. The evaporation effect is modeled by the use of the thermal boundary condition and mass balance equation at the interface. The anomalous thermocapillarity effect at the interface is also taken into consideration. For the n-heptanol-nitrogen systems the velocity profiles that characterize the fluid flows are presented. The effects of gravity and the longitudinal temperature gradient along the interface on the fluid flows are investigated. The obtained results demonstrate the quantitative and qualitative differences in the flow of liquid in the case of normal and anomalous thermocapillary effect and also in the conditions of normal and low gravity.

Authors gratefully acknowledge the support of this work by the Russian Foundation of Basic Research, grant 14-08-00163.

\section{References}

[1] O.N.Goncharova, M.Hennenberg, E.V.Rezanova, O.A.Kabov, Modeling of the convective fuid fows with evaporation in the two-layer systems, Interfacial Phenomena and Heat Transfer (IHMT), 1(2013), 389-396.

[2] O.N.Goncharova, E.V.Rezanova, Example of an exact solution of the stationary problem of two-layer flows with evaporation at the interface, Journal of Applied Mechanics and Technical Physics, 55(2014), no. 2, 247-257.

[3] O.N.Goncharova, Yu.V.Lyulin, E.V.Rezanova, O.A.Kabov, Modeling of the stationary problem of two-layer flows of the liquid and gas by evaporation, Journal of Thermophysics and Aeromechanics, 22(2015), no. 5, 655-661.

[4] M.I.Shliomis, V.I.Yakushin, Convection in a two-layers binary system with an evaporation, Collected papers: Uchenye zapiski Permskogo Gosuniversiteta, seriya Gidrodinamika, 4(1972), 129-140 (in Russian).

[5] R.V.Birikh, Thermocapillary convection in a horizontal layer of liquid, J. Appl. Mech. Tech. Phys., 3(1969), 43-45.

[6] Yu.V.Sanochkin, Some problems of thermocapillary fluid flows, Prikladnaya Mechanika $i$ Technicheskaya Fizika, 5(1989), 83-88 (in Russian).

[7] V.V.Popov, Mixed convection in a two-layer liquid, Theoretical principles of chemical technology, XV(3)(1981), 398-404 (in Russian).

[8] V.K.Andreev, V.B.Bekezhanova, Stability of the non-isothermal fluids, Krasnoyarsk, Siberian Federal University, 2010 (in Russian).

[9] G.A.Ostroumov, Free convection in the conditions of the internal problem, Moscow, Leningrad: Gos. izd-vo tehniko-teoreticheskoy literatury, 1952 (in Russian).

[10] V.K.Andreev, Yu.A.Gaponenko, O.N.Goncharova, V.V.Pukhnachov, Mathematical models of convection (de Gruyter Studies in Mathematical Physics), Berlin/Boston: De Gruyter, 2012. 
[11] B.Gebhart, Y.Jaluria, R.L.Mahajan, B.Sammakia, Bouyancy-induced flows and transport, Berlin, Heidelberg, New York, London, Paris, Tokyo, Springer Verlag, 1988.

[12] M.Cl.Limbourg-Fountaine, G.Petre, J.-C.Legros, Texus 8 experiment: Effects of a surface tension minimum on thermocapillary convection, Physicochemical Hydrodynamics, 6(1985), no. $3,301-310$.

[13] J.-C.Legros, M.Cl.Limbourg-Fountaine, G.Petre, Surface tension induced convection in presence of a surface tension minimum, Physicochemical Hydrodynamics, Interfacial Phenomena. In M.G. Velarde Ed., NATO ASI series, Series B: Physics, New York, Plenum Press, 174(1988), 209-227.

[14] G.Petre, M.Cl.Limbourg-Fountaine, J.-C.Legros, Study of the surface tension minimum of aqueous alcohol solutions and movements at the interface air/solution, Proc. of the 4th Europ. Symp. on Material and Sciences under microgravity, Madrid, Spain, 5-8 April 1983, 199-200.

[15] A.Cloot, G.Lebon, Marangoni convection induced by a nonlinear temperature-dependent surface tension, J. Physique, 47(1986), 23-29.

[16] R.Savino, A.Cecere, R.Di Paola, Surface tension-driven flow in wickless heat pipes with self-rewetting fluids, Int. J. Heat and Fluid Flow, 30(2009), no. 2, 380-388.

[17] O.N.Goncharova, Yu.O.Kabova, O.A.Kabov, Thermocapillary convection in a free liquid layer in the presence of an adjacent gas flow, Computational Thermal Sciences, 5(2011), no. 3, 389-396.

[18] A.A.Ravdel, A.M.Ponomareva, Hand-book of physico-chemical quantities, Sankt-Peterburg, Specialnaya literatura, 1998 (in Russian).

\section{Моделирование двухслойных течений с испарением на границе раздела при наличии аномального термокапиллярного эффекта}

\section{Ольга Н. Гончарова Екатерина В. Резанова}

\footnotetext{
Стационарные конвективные течения двух несмешивающихся жидкостей (жидкости и газа), находящиеся под действием поперечного поля силь тяжести и продольного градиента температуры, созданного вдоль границы раздела, изучаются аналитически. Математическое моделирование течений жидкостей с учетом эффектов испарения на границе раздела проводится на основе точных решений системь уравнений Навъе-Стокса в приближении Обербека-Буссинеска. Учитываются также эффекты термодиффузии и диффузионной теплопроводности. Построенные решения применяются для описания течений в двухслойной системе жидкости и газа в случае, когда жидкость характеризуется аномальным термокапиллярным эбфектом на границе раздела. Приводятся примеры двухслойных течений при различных значениях удельного расхода газа, продольного градиента температуры и ускорения силы тяжести.
}

Ключевые слова: математическая модель, граница раздела, испарение, точное решение, аномальный термокапиллярный эффект. 